\title{
Impact of University Campus Design on Local Urban Development and Sprawl: A Case Study Analysis of Albaha University, Saudi Arabia
}

\author{
Naief Ali Aldossary", Khalid Abdullah Alkhuzai \\ Faculty of Engineering, Albaha University, Albaha, Saudi Arabia
}

Email address:

dr_naief@hotmail.com (N. A. Aldossary), khalid626@gmail.com (K. A. Alkhuzai)

\section{To cite this article:}

Naief Ali Aldossary, Khalid Abdullah Alkhuzai. Impact of University Campus Design on Local Urban Development and Sprawl: A Case Study Analysis of Albaha University, Saudi Arabia. Urban and Regional Planning. Vol. 6, No. 2, 2021, pp. 68-78. doi: 10.11648/j.urp.20210602.12

Received: February 28, 2021; Accepted: March 25, 2021; Published: April 16, 2021

\begin{abstract}
The paper investigates and analyses the urban design of the Albaha University campus from an economic and environmental perspective. With coronavirus pandemic, the education protocol, precautionary measures and social distance have been applied in order to achieve safety environment within the university boundary. The study analyses the university campus design in light of sustainable requirements, social distance protocol, employment of natural resources and application of urban sustainable design criteria. Regional urban planning and development needs to include attraction factors to boost the economy and trigger reverse migration. Establishing a university in the region helps significantly in terms of local urban growth but environmental aspects including energy conservation and management should also be considered for environmental reasons. The approach used in this study involved: (a) an environmental site analysis including an analysis of natural resources such as the wind, solar energy and annual rainfall to determine how such resources can be employed in the operation of the university; (b) a site visit survey analysis to investigate the sustainable use of the current facilities and open spaces of the university campus and the application of on-site renewable energy; and (c) a SWOT analysis to determine the role of the university in the local economy system. The urban sustainable design and possibility of using landscaping, shading devices, and solar radiation systems was investigated through building plans and a site visit to the campus. In addition, the form and fabric of the academic buildings was investigated to identify the application of shading devices, the windows design and use of insulation. The study highlights the fact that many buildings are still under construction while other buildings are still currently on plan. The paper concludes by giving some recommendations from an economic and environmental perspective.
\end{abstract}

Keywords: Urban Sustainable Design, University Campus, Energy Conservation, Environmental Design

\section{Introduction}

The Albaha region is characterised by its cooler climate, its agriculture [1] and its significant role in the tourism sector of Saudi Arabia [2]. Furthermore, Albaha is rich in natural resources and minerals compared with the other provinces of Saudi Arabia where the tourism and agriculture have a great impact on the local economy. Historically, locals leave the region for specific reasons such as to continue their education at a university; this is one of the main reasons for local migration from a region to another region that has a university. The establishment of the Albaha University in 2006 was an important step in the development of the region as it helped contribute to the local economy. It also not only prevented local migration but contributed to reverse migration that resulted in urban growth and development and encouraged local investment. To date there has not been an assessment of the university's design based on the local climatic conditions and challenges, or its contribution to the region's economic development and its performance in terms of the competition provided by the universities in nearby regions.

This paper investigates and analyses the urban planning and design of the Albaha University campus, its open spaces and facilities, its building mass in terms of the climatic conditions, the potential employment of natural resources to partially operate its facilities and the role of the university and its facilities within the local economy and society. The paper is divided into five main categories (a) the introduction; (b) the research approach; (c) the results and analysis; (d) the 
discussion and (e) the conclusion and recommendations.

\section{Research Approach}

To investigate the current urban condition and long-term plan for the Albaha University campus, it was essential to perform a physical analysis of the university campus. A site visit and survey analysis was conducted with the following objectives:

1) Objective one: To investigate the current facilities, its ability to perform social distance and identify future needs.

2) Objective two: To investigate the current urban design and exploitation of and investment in the open spaces within the university campus.

3) Objective three: To identify the sustainability of the campus and use of natural resources within the local environment.

A site visit and survey analysis was conducted to investigate the applied urban design of the university campus, specifically, the surrounding features, climatic conditions and characteristics of Albaha. Furthermore, particular attention was paid to how open spaces were used within the university campus in order to put forward recommendations on how they can be further exploited and to recommend the facilities that could be introduced based on the numbers of university faculty and students. The SWOT and PESTEL approaches were used to investigate the use of current facilities within the university and identify how the suggested facilities could influence the university's urban design [3]. Many studies have employed the SWOT analysis approach to come up with energy and climate policies [4] and for strategy urban planning and design $[5,6]$. The techniques applied in this method are as follows:

1) Physical site visit and survey analysis: A site visit survey was conducted to identify and analyse the current status of each individual building within the university campus. The information gathered included the use of the buildings and the facilities therein, the number of students according to university records and a record of the open spaces and their use. The survey also covered an environmental analysis and visual exploration. This approach helps analyse the current situation of a building based on its current condition, environmental requirements as well as urban and economic challenges.

2) Urban design and environmental analysis: This investigation concerned an analysis of the application of sustainability criteria in the design of the university campus including the topography; the building mass and envelope of individual buildings; the landscape design; and, the application of on-site renewable energy and water management systems. The approach also employs an analysis of the actual layout of the university campus against current environmental and social needs.

3) SWOT analysis approach: The SWOT approach was employed in this study to determine the impact of the university and its facilities on urban sprawl and growth. The economic and social role of the university campus in the Albaha region was assessed, specifically in terms of the contribution of the university to the economy of Albaha against the investment required [7, 8]. Figure 1 summarises the three stages of the study.

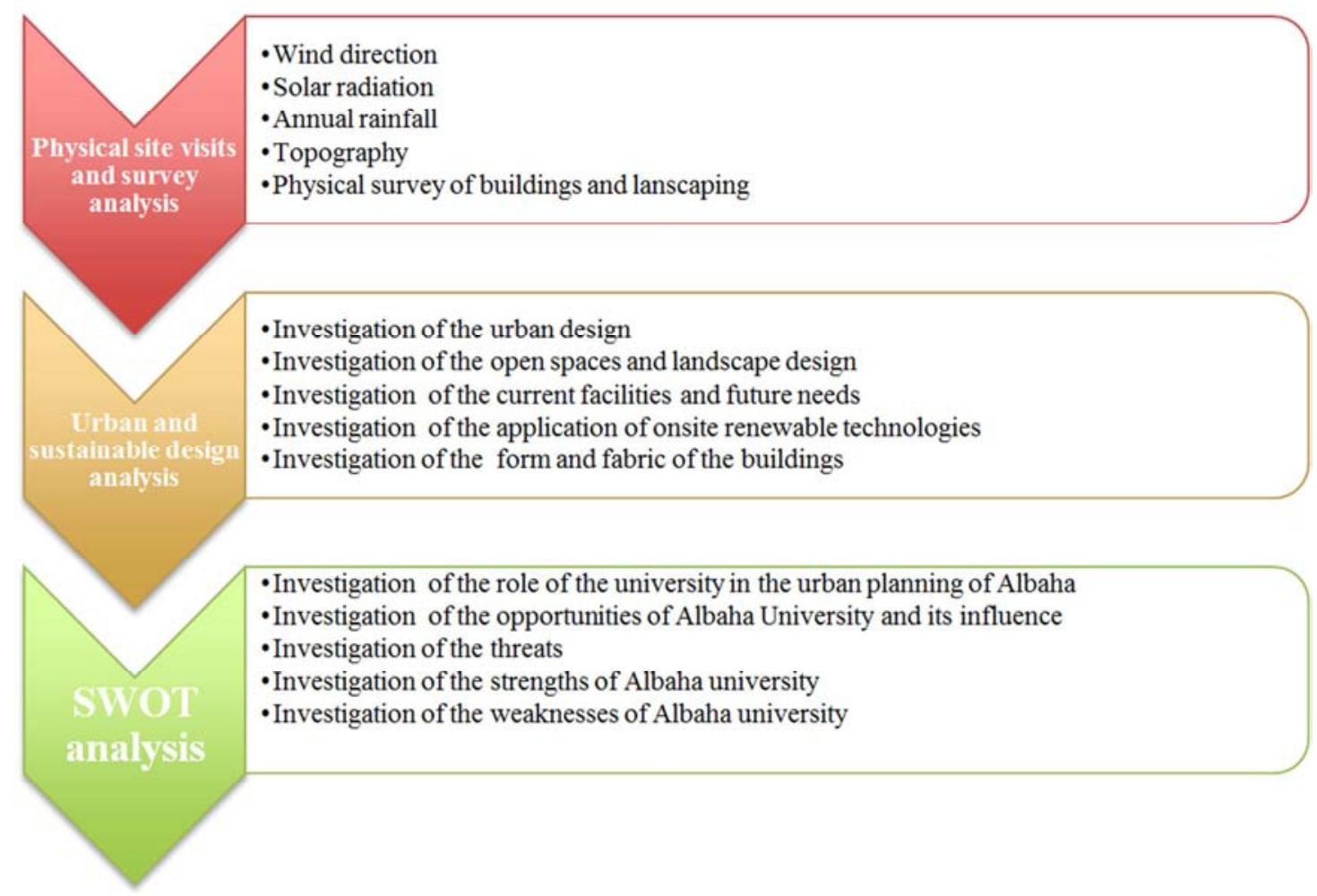

Figure 1. Approach used in the study. 


\section{Results and Analysis}

The approach involved a site visit to the university campus to evaluate the construction design of the colleges, accommodation buildings and the administrative building. Many issues were observed during the physical survey and the evaluation of open spaces, urban design and the construction plans of the university campus. The analysis will be presented in three parts, namely: (a) an environmental site analysis of the university campus; (b) an urban and sustainable design analysis; (c) the role of the university in the urban planning policy of Albaha: a SWOT analysis.

\subsection{Physical Site Visits and Survey Analysis}

A survey of the university topography was conducted to establish the current situation of the university campus. This survey established that when the university was designed the urban and site conditions were not taken into account. The university site contains mountains within its boundary. This meant that the mountain had to be cut into to fit in some of the buildings (e.g. staff accommodation) resulting in additional construction work and increased $\mathrm{CO}_{2}$ emissions caused by the extra construction work and the transportation of the rock that was excavated. Figure 2 presents the site analysis of the university campus.

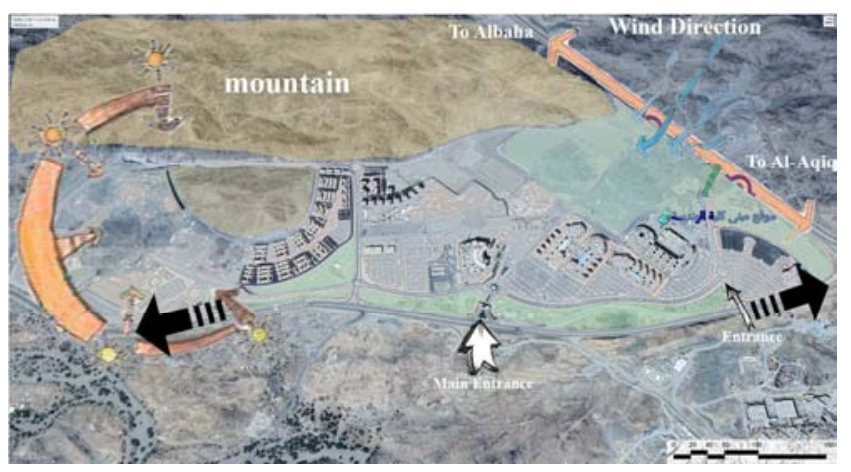

Figure 2. Environmental site analysis.

The topography of the university site can be seen in Figure 2. It shows how important it is that the design of a building, such as a university, takes into account the challenges provided by the site in order to ensure an efficient design requiring fewer costs and causing fewer $\mathrm{CO}_{2}$ emissions, to protect the environment. As seen in Figure 2 an area of the site is completely covered by mountains and this is the area which was earmarked for the construction of accommodation for staff members. This area could have been exploited by placing other buildings in it that could have exploited its features such as gym facilities or a restaurant with the best view of the university.

The analysis included an environmental analysis that takes into account the wind direction, the sun path and annual rainfall. Rainwater harvesting is a technique that could have been implemented at the university given its environmental conditions and the fact that rain is a natural resource [9]. Figure 3 presents the average Monthly rainfall in the Albaha region (source: weatherspark.com).

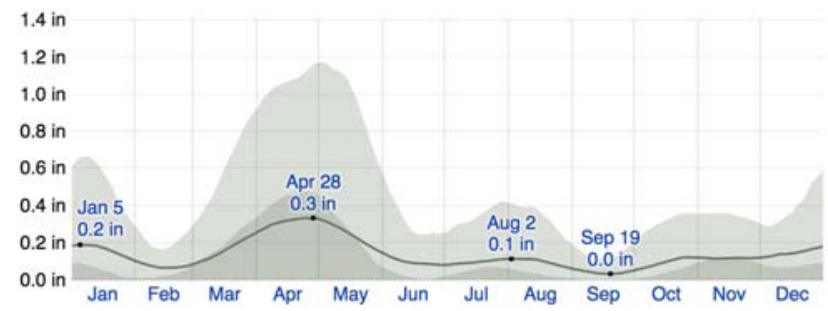

Figure 3. Annual rainfall in the Albaha region.

Rain water could be used for irrigation of the university's open spaces and parks. The quantity of rain water that could be harvested annually can be calculated using the simple formula (area $*$ annual rainfall $\mathrm{mm} * 0.9=$ Liter). Buildings roofs and some of the campus' open spaces could be exploited for this purpose and help the university meet some of its environmental requirements.

\subsection{Urban and Sustainable Design Analysis}

It is well known the urban design must focus and deal with the local topography and climatic conditions. The Albaha region is a mountainous region characterised by cool climatic conditions in contrast to other regions of Saudi Arabia. The university design focused on the need to build colleges and other facilities, ignoring the environmental design and failing to deal with the local site conditions. Figure 4 presents the visual analysis of the university campus.

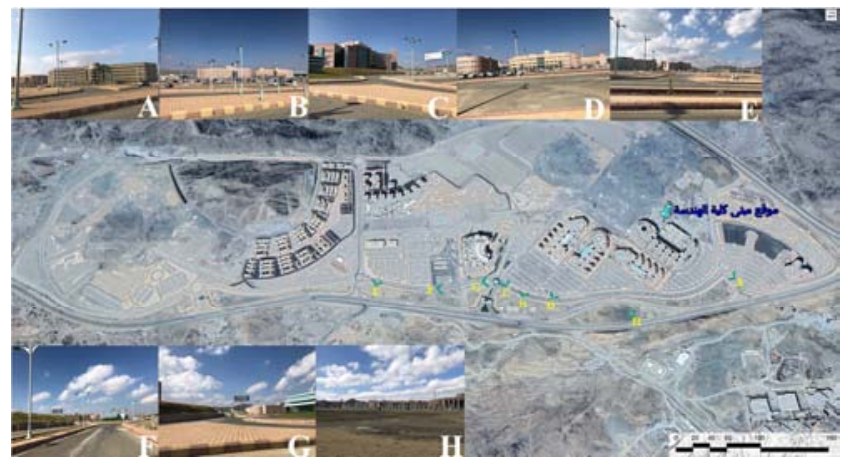

Figure 4. Visual analysis of the university campus.

As shown in Figure 4, there are huge open spaces that are not exploited for social or investment purposes. The university facilities are used by students aged between 18 and 23 years. This means that they need facilities such as a gymnasium, a theater and other public spaces including coffee shops and other places where they can meet. Furthermore, the green areas around the buildings need to be considered as part of the environmental design to reduce energy consumption. Figure 5 displays the open spaces within and around the university that can be developed and the facilities that can be built to contribute to the university 
and to local development. The open spaces within and around buildings still need to be developed and / or planted with trees and grass to cool the surrounding areas and provide shade.

More facilities need to be allocated within the university boundary due to increasing student and staff needs. These facilities can be integrated with the open spaces that have not been allocated to particular uses. The survey identified the current uses of facilities, sites and buildings within the university campus. Table 1 lists the current buildings and facilities within the university campus.

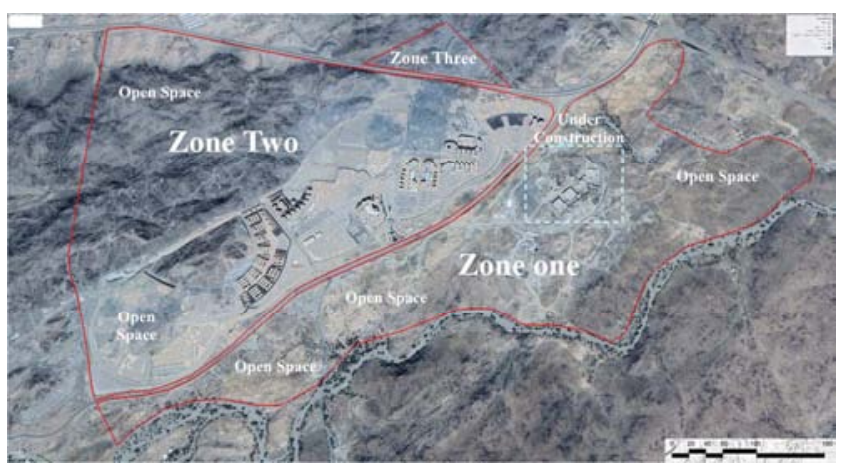

Figure 5. Open space analysis.

Table 1. Buildings and facilities within the university campus.

\begin{tabular}{|c|c|c|}
\hline Facility & Number of buildings & Description \\
\hline Academic buildings & 5 buildings & $\begin{array}{l}\text { Contains } 10 \text { colleges } \\
\text { 1) } 6 \text { Deanships } \\
\text { 2) } 7 \text { Administration offices }\end{array}$ \\
\hline Administration buildings & 1 building & $\begin{array}{l}\text { 3) University Rector's office } \\
\text { 4) } 4 \text { Vice Presidents' offices } \\
\text { 5) Temporary library and mosque }\end{array}$ \\
\hline Academic staff accommodation & 112 Buildings & 99 houses and 13 apartment buildings with a total of 209 residential units \\
\hline Restaurants as individual buildings & Under planning & Under planning \\
\hline Coffee shops and facilities as individual buildings & Under planning & Under planning \\
\hline Accommodation facilities and schools & Under planning & Under planning \\
\hline Hospital & Under construction & Under construction \\
\hline Main Library as individual building & Under planning & Under planning \\
\hline Student Centre as individual building or section & Under planning & Under planning \\
\hline Gymnasium & Under planning & Under planning \\
\hline
\end{tabular}

It is essential to plan the future needs of the university. The university is located between the cities of Albaha and Al-Aqiq and urban and transportation issues need to be taken into account. Developers can invest to meet the needs of student life and the environment. Accommodation facilities can accommodate up to 570 students; they will need support facilities such as a laundry and shops.

Future plans need to take into account the envisaged growth of the student population in order to allocate the area needed and draw up suitable designs for the facilities on campus. Table 2 shows the number of students according to gender that currently attend the university.

Table 2. Student population.

\begin{tabular}{lclll}
\hline \multirow{2}{*}{ Saudi } & \multirow{2}{*}{19339} & $\begin{array}{l}\text { Male } \\
\text { Female }\end{array}$ & 8877 & 10426 \\
Non Saudi & \multirow{2}{*}{216} & $\begin{array}{l}\text { Male } \\
\text { Female }\end{array}$ & 154 & Total: 19555 \\
\hline
\end{tabular}

The characteristics of the student body in terms of gender and faculty allocation helps inform design. Female students, for instance, were not taken into account in the design of the campus and the allocation of facility centres within the main university campus with the result that they have to study in a different place located about 10 miles away from the university. Figure 6 presents the student percentage in each faculty to identify the total percentage of students who study in the main university campus.

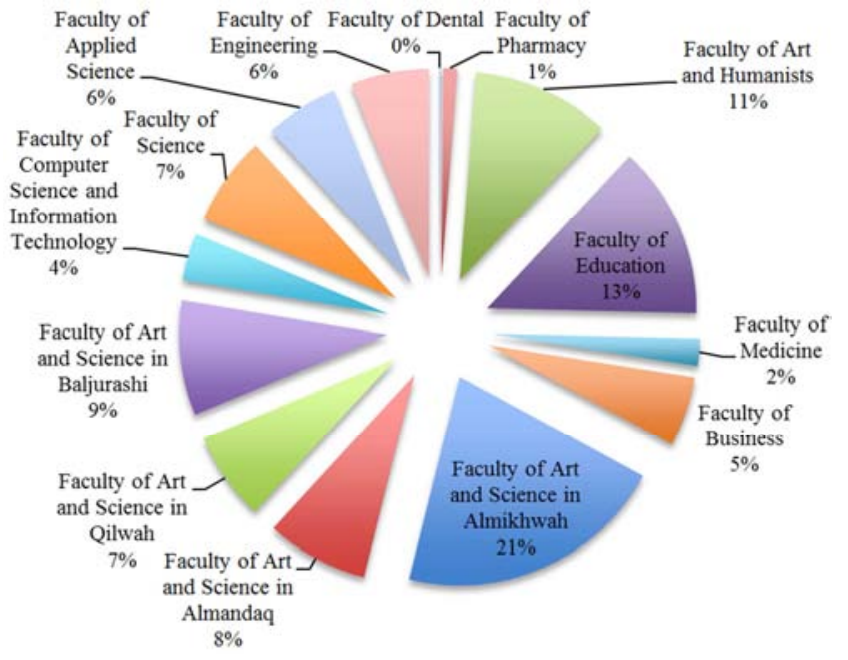

Figure 6. Student percentages per faculty.

1) Building mass and design

Since the external wall system plays a significant rile in energy conservation and deal with the aggressive local environment $[10,11]$. The external envelope of the building, that is the walls, doors, windows and ceiling, play an important role in managing the building's energy demand by managing and minimising heat transference from the external atmosphere to the internal $[12,13]$. Some sustainable design principles were applied in the design of the colleges and the 
administrative building. Energy consumption in buildings can be minimized through high efficient external glazing that reduces heat transmission from the internal to the external atmosphere (heat loss) and allows heat gain through natural lighting (daylight). External glazing exploits solar radiation and controls heat loss, which is suitable for buildings in cooler climates. This type of glazing can be achieved by the application of multiple glazing with argon gas between the glass panes to reduce and eliminate heat transference [14]. In order to minimise the energy consumption in building it is important to implement the phase change material used in the applied external glazing system $[15,16]$. This can contribute to an improvement in the efficiency of solar energy, which can lead to more efficiency in thermal performance [15].

The double-glazing technique was applied in the design and construction of some buildings in the university campus. This plays an important role in minimising heat transference from the external to the internal atmosphere. Minimising thermal transmission from the outside to the inside of a building will result in less energy consumption in the buildings. Figure 7 presents the buildings' fabric design of the university while Figure 8 presents the External glazing used in the buildings within the university campus.

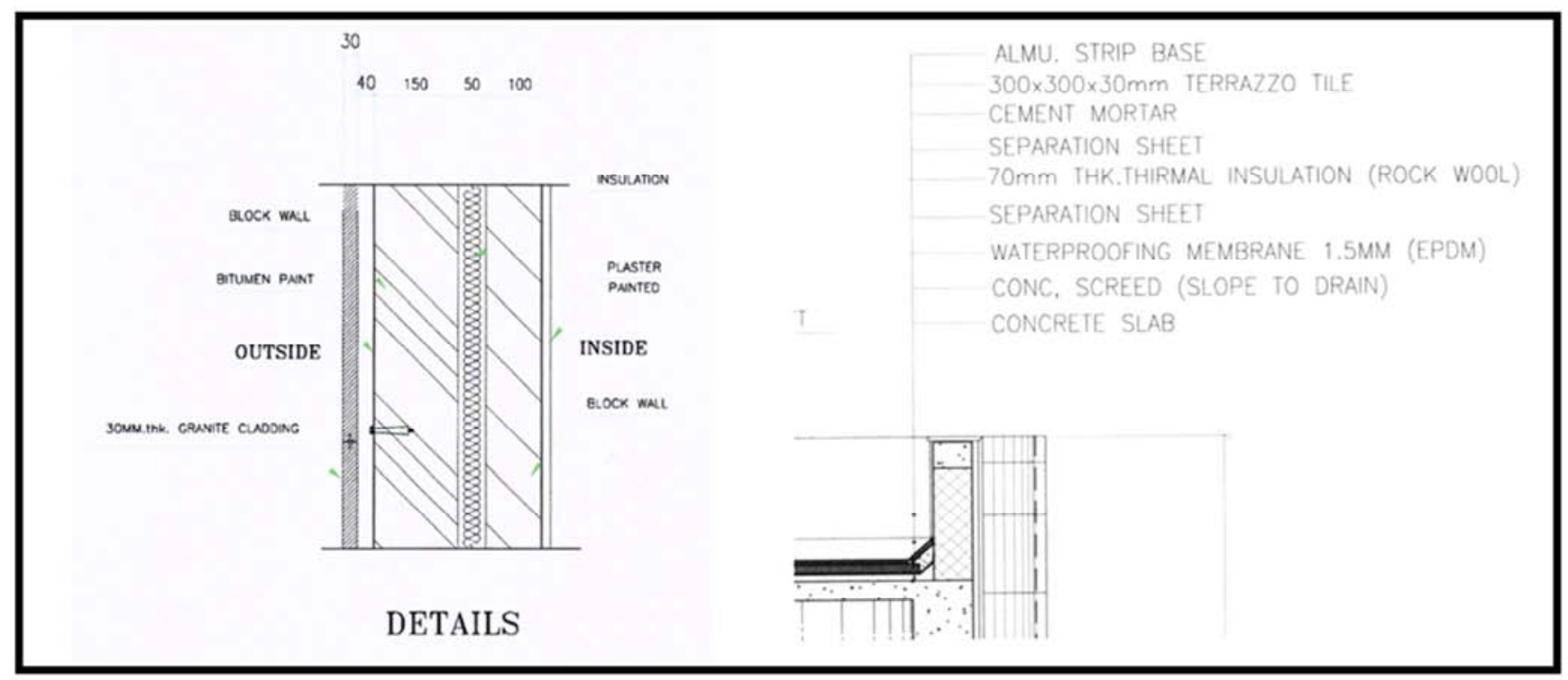

Figure 7. Building's fabric designs of the university facilities and colleges.

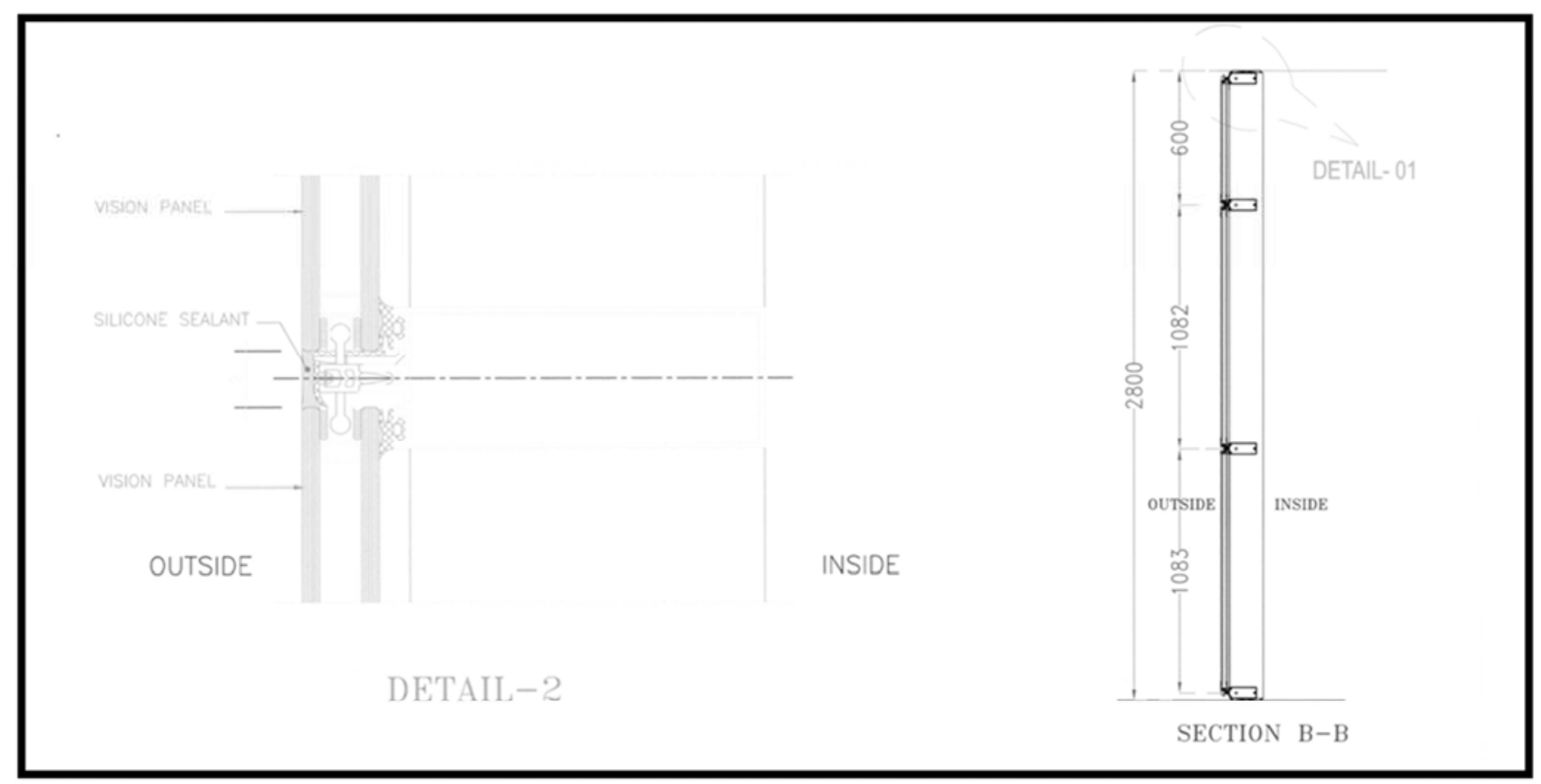

Figure 8. External Glazing designs of the university facilities and colleges.

The building envelope is designed with the cost and availability of construction material in mind [17]. Most of the 
university buildings used the same designs and construction materials. Each region in Saudi Arabia is characterised by its local urban identity. Urban identity characteristics arise from local culture and societal norms; however, recent changes to urban identity include shifts in terms of environmental conditions and cultural style [18]. The construction materials used must be able to deal with the local climatic conditions as well as be manufactured out of local raw materials. The key efficiency factor of the selected construction materials is heat transmission. Stone is a local construction material that has a high efficiency in terms of reduction of heat transference that results in minimising energy which is the concept behind air conditioning.

2) Energy supply and generation

The energy source that operates the university and its facilities is electricity provided by the Ministry of Electricity. During the site visit at the university campus it was observed that the university's energy demand was more than the electricity provided by the Ministry of Electricity. The electricity grid does not cover the whole university campus and its facilities with the result that some facilities are not operated. The staff accommodation, for example, is already built and completely finished but is not used because of the lack of energy. It will take money, time and a framework plan to build a switching station to get energy from the main supplier. This indicates the importance of finding an alternative energy supply. The Albaha region is rich in solar radiation and can provide energy in the form of electricity generated through solar heat [19]. Fable 9 illustrates the availability of solar heat in Saudi Arabia [20].

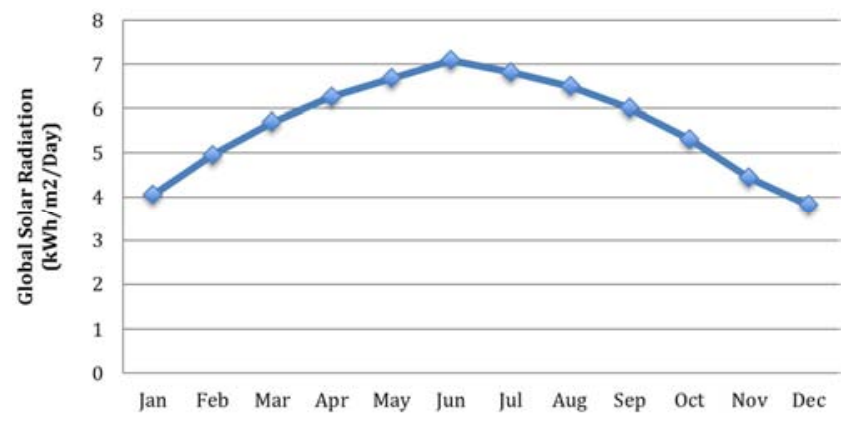

Figure 9. Seasonal variation of global solar radiation over Saudi Arabia.
The survey highlighted a lack of on-site renewable energy sources. Albaha region is rich in solar radiation and this natural resource can be employed to operate buildings on the university campus and minimise the energy demand from the Ministry of Electricity as well as reduce $\mathrm{CO}_{2}$ emissions. Photovoltaic (PV panels) can be set up at the university campus in the open spaces, car parks and on the roofs of the accommodation buildings. The amount of energy generation varies depending of climatic conditions and the efficiency of the PV system [21].

\subsection{Role of the University in Urban Planning of Albaha: SWOT Analysis}

In order to investigate the role of the university in the region, in light of the investment that has been put in it and urban growth, the SWOT and PESTEL analysis approaches were used. Figure 10 below illustrates the PESTEL as a powerful complement to SWOT.

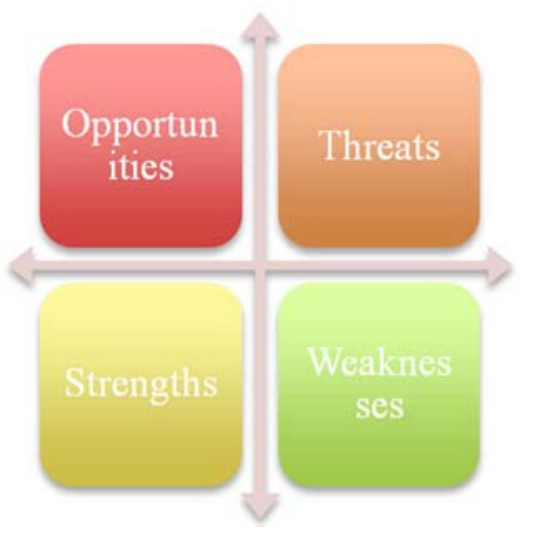

Figure 10. PESTEL as a powerful complement to SWOT.

The physical survey analysis identified many strengths and weaknesses of the university. Among its strengths is the fact that there is only one established government university in the Albaha region that offers a mix of applied science, basic science, medicine, engineering, education and social science courses. Table 3 below presents the details of the PESTEL approach.

Table 3. PESTEL powerful complement to SWOT.

\begin{tabular}{|c|c|}
\hline Opportunities & \\
\hline 1) Establishing course subject in accordance to market demand and local & Threats \\
\hline $\begin{array}{l}\text { economy requirements (i.e. mining engineering; tourism; agriculture; } \\
\text { agronomy and archeology). }\end{array}$ & 1) Competition from other universities in regions close to Albaha (i.e. King \\
\hline 2) Investing in facilities that participate in the local economy and the university & Khaled University; Bisha University and Taif University). \\
\hline (i.e. hotel; shops and laboratories). & 2) Low population and investors in the region. \\
\hline $\begin{array}{l}\text { 3) Involving local decision makers in the development of the region by providing } \\
\text { consulting services. }\end{array}$ & 3) Lack of companies and factories that contribute to the economy. \\
\hline 1) No competition from other universities in the region. & 1) Lack of laboratories in some subject fields such as mechanical \\
\hline 2) Availability of natural resources to establish new subject fields such as & engineering and medicine. \\
\hline Agriculture and Mining Engineering. & 2) Loss of some academic members to some other universities and industries. \\
\hline 3) Availability of human resources who graduated from different international & 3) Some subject fields still being established. \\
\hline universities across the world. & 4) Some faculties still under construction, such as Faculty of Engineering. \\
\hline $\begin{array}{l}\text { 4) Availability of natural resources to invest and support local companies in the } \\
\text { field of industrial engineering and applied. }\end{array}$ & $\begin{array}{l}\text { 5) Some faculties still located far away from the university campus, such as } \\
\text { Faculty of Education. }\end{array}$ \\
\hline
\end{tabular}


As seen, the university plays a significant role in the local urban planning, investment and economic system. Some weaknesses were identified that can be addressed to achieve the main target of establishing the university and developing the local urban environment. One of the steps to be considered is the development of new courses and faculties that deal with the specific characteristics of the Albaha region, such as a Faculty of Agriculture, Food and Environment that focuses on the management of the region's natural resources, water and agricultural features. The strengths of the university also need to be developed to counteract the threats that the university faces. The surrounding universities pose threats that can affect the university's position in local urban planning. Other options are available to the public that offer the same quality of education; developing the university's strengths and providing unique courses tailored to the Albaha region will play a significant role in the urban development of the region.

\subsection{Social Distance Application and Coronavirus Protocol}

Coronavirus palays a significant role in changing the systems that academic institutes function worldwide. The university has conducted some roles and procedures for safety in the case of covid-19 pandemic. It is important to notice that, Social distance and e-learning were the first step procedure has been taken by the university as well as some clinical procedures and public awareness. The Covid-19 pandemic played a significant role in education system and created some additional process in academics institutes in Saudi Arabia. The education system has been changed in the light of pandemic challenges where e-learning is conducted remotely online. Albaha university has taken e-learning through Virtual lectures for courses at the university. On another hand, Social distance at the university has been conducted as a safety procedure. It is well know that, most of instates applies physical distance to avoid infection of Covid 19. Hence, Increasing the physical distance among students is important and can participate in reduction of transmission of the coronavirus. The university has raised the awareness to practice and follow physical distance between students. Figures 11 and 12 illustrate the practice of university of application social distance between students in labs.

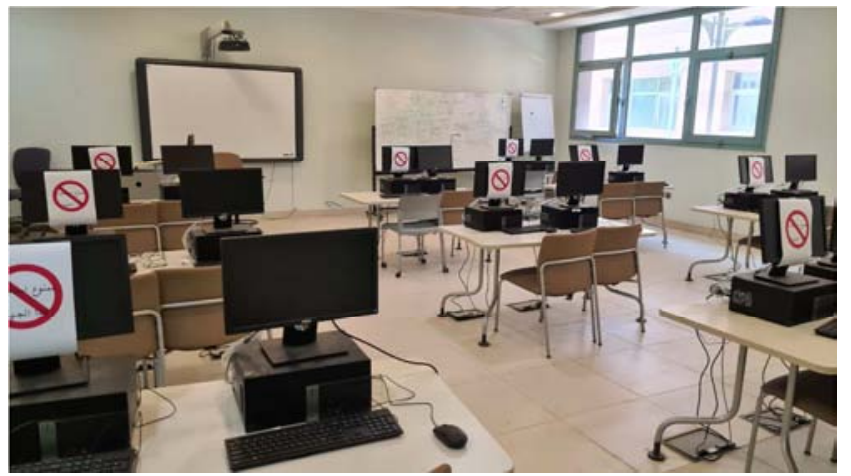

Figure 11. Social distance procedure in labs.

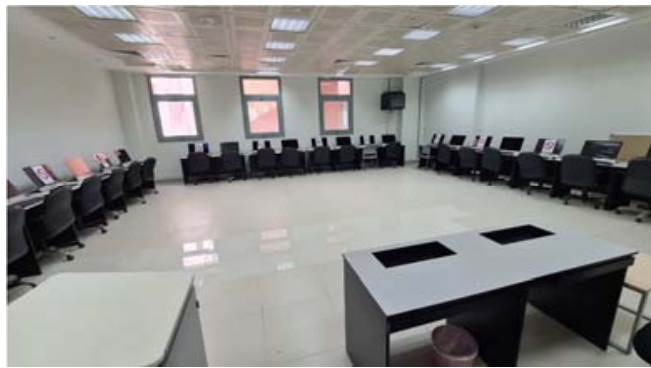

Figure 12. Social distance procedure in labs.

\section{Discussion}

The discussion that follows on the basis of the analyses will focus on three main categories: (a) the urban sustainable design of the university campus; (b) the development design of the university, and (c) an assessment of environmental performance and the application of on-site renewable energy technology.

\subsection{Urban Sustainable Design of the University Campus}

It is essential to focus on the environmental design of the university that involves the outdoor design of the university campus and the indoor design of each individual building in terms of energy performance and minimisation of energy consumption. Energy conservation in a built environment is an important target to be achieved [22-25]. In the past 40 years, sustainability has become an issue of greatest importance. The sustainability of the university campus is important for the university's academic members, scholars, students and practitioners [26].

Many university campuses face mobility issues caused by the extreme use of private vehicles by the university staff members as well as students $[27,28]$. Investment in the open spaces within the university campus is essential. Dell'Oio, Cordera et al. (2018) used the survey analysis approach to determine the impact of variables and changes on users' mobility options to simulate their behaviour on policies by, for example, employing new transportation modes or introducing fees for car parking in the campus. They found that introducing fees at the car park on the university campus is a serious deterrent to private car use which, in turn, contributes to sustainable mobility and transportation management [27]. In addition, money earned through car parking fees would contribute towards investment in these open spaces and could be used to strengthen the sustainable mobility policies of the university campus [27].

\subsection{Development Design of the University Campus}

The open spaces within and around the university make it easier to create a cooler environment by designing optimal parks [29]. Efficient landscaping, including good use of trees, plants and green areas, would significantly help provide a naturally cooler environment by minimising the air temperature and balancing the humidity level [30-32]. Since Saudi Arabia is hot, it is essential to provide an efficient external landscaping design and employ natural ventilation 
systems to cool the external atmosphere. Moreover, an external cool environment can be achieved by distributing the trees and green area. This will contribute to a reduction of energy demand for cooling systems in the buildings of the university $[33,34]$. As seen in the master plan of the university campus, there is no exploitation of the huge open area around and within the campus. These areas are not allocated to any future projects or extensions to the university. Hence, these areas can be allocated as open space areas for social activities as well as environmental purposes, as described below;

1) For social activities:

The open space areas can be invested in and socially exploited through an efficient landscaping design that creates a comfortable atmosphere. As mentioned in the analysis, the university comprises over 12,000 students distributed among the university schools and facilities. These students can be attracted to open spaces especially when attractive facilities are provided by the university or investors. Coffee shops, fountains including seating areas surrounded by green areas will attract students to these areas between lectures and during break times. Furthermore, there is a long distance between the parking areas and the university facilities. The pathways links must be constructed and prepared to meet thermal comfort guidelines so that they can be used for walking. Planting and efficient landscaping is the best solution to meet the social requirements of such external open spaces.

2) Environmental requirement:

Efficient landscaping of the external open spaces and areas will help meet environmental and sustainable requirements $[35,36]$. The employment of natural resources such as "natural ventilation" will help minimise $\mathrm{CO}_{2}$ emissions as well as reduce the energy demand [37] which is an important urban sustainable factor. Ensuring external shading, natural ventilation and trees will help create a cooler atmosphere and reduce the energy demand of the cooling systems used. Solar radiation using HVAC (heating ventilation air conditioning) principles can be used depending on the efficiency of the shading devices used and the user profiles of the buildings.

\subsection{Application of Assessment Tools}

One of the methods used to assess the efficiency of buildings in terms of environmental criteria as well as cost and embodied energy is the environmental assessment approach that is used in the designing stage $[38,39]$.

A number of Environmental Assessment Methods of Buildings (EAMB) had emerged all over the world, and a number of global variables affect the estimation of the assessment item weights in those methods. Many environmental assessment schemes have been established to manage and control the built environment in terms of reducing energy consumption, minimising $\mathrm{CO}_{2}$ emissions and meeting environmental sustainability standards. These schemes are used across the world and some global variables impact on the evaluation of the assessment and evaluation item weights in these methodologies [40].

The variety of environmental assessment schemes has increased in the past twenty years. BREEAM was the first environmental assessment method used in the UK. It was launched in 1990 to meet environmental requirements and help achieve sustainable low carbon energy buildings. It was followed by many other environmental assessment methods based on the local environment, culture and life style. BREEAM was designed to be used by engineers, contractors and developers as well as owner-occupiers. Another environmental assessment approach is the Leadership in Energy and Environment Design (LEED) which was launched in 1998 in the US. The Comprehensive Assessment System for Building Environmental Efficiency (CASBEE) was subsequently launched in 2004 in Japan. Each of these programmes has its own methodology and criteria of evaluation, assessment and scoring of the buildings. Table 4 below provides a comparison and details of the scoring and rating system of each scheme as applied in four different countries across the world [41]. Currently, BREEAM and LEED are the most commonly applied environmental assessment schemes for buildings, with the aim being to achieve more environmental and sustainable buildings within the construction industry [42-44]. Other schemes include KASBEE in Japan and the Green Star in Australia. An environmental assessment approach can control and manage the design and construction process to ensure that the building is constructed in a way that makes best use of the local environment in terms of climatic conditions and natural resources.

Table 4. Assessment scheme in some developed countries [41].

\begin{tabular}{|c|c|c|c|c|}
\hline & LEED & BREEAM & KASBEE & GREEN STAR \\
\hline Place of origin & USA & UK & Japan & Australia \\
\hline Year of launch & 1998 & 1990 & 2004 & 2003 \\
\hline Rating method & $\begin{array}{l}\text { 1) Certified } \\
\text { 2) Silver } \\
\text { 3) Gold } \\
\text { 4) Platinum }\end{array}$ & $\begin{array}{l}\text { 1) Pass } \\
\text { 2) Good } \\
\text { 3) Very good } \\
\text { 4) Excellent } \\
\text { 5) Outstanding }\end{array}$ & $\begin{array}{l}\text { 1) } \mathrm{C} \\
\text { 2) } \mathrm{B}- \\
\text { 3) } \mathrm{B}+ \\
\text { 4) } \mathrm{A} \\
\text { 5) } \mathrm{S}\end{array}$ & $\begin{array}{l}\text { 1) One star } \\
\text { 2) Two stars } \\
\text { 3) Three stars } \\
\text { 4) Four stars } \\
\text { 5) Five stars } \\
\text { 6) Six stars }\end{array}$ \\
\hline
\end{tabular}

It was noted that no assessment tool was applied in the design of the Albaha campus either in the design stage or the construction process. The Albaha University must be designed on the basis of local climatic conditions, availability of construction materials as well as the urban growth plan. Transporting construction materials creates embodied energy resulting in increased $\mathrm{CO}_{2}$ emissions which does not fit in with sustainable requirements. 


\subsection{Renewable Energy Application}

One of the most important principles in environmental design is the employment of natural energy sources such as wind and solar radiation [45]. According to Rehman and Bader et al. (2007) [20] who charted solar energy (radiation) and sunshine duration data to investigate the availability of this natural energy and sunshine period across the Kingdom of Saudi Arabia, Saudi Arabia is rich with solar radiation. Solar radiation varies depending on the location and climatic conditions. On this basis, solar radiation can be employed in the university campus to operate some buildings that are not served by the electricity network. The use of photovoltaic systems has increased in the last few years [46] in the EU, the USA, Australia and Asia. Metadata from 2,802,797 photovoltaic systems located in the US, Australia Europe and Japan indicates $59 \mathrm{GWp}$ of total capacity [47]. Hence, due to the availability of a high amount of available solar radiation, this technology can be employed in the Albaha University. A photovoltaic (PV) energy generation system can be applied to partially operate the accommodation section by turning solar radiation energy into electricity. Bertrand, Housmans et al. (2018), who evaluated the opportunity of exploiting global solar radiation by implementing photovoltaic (PV) systems in Belgium [48], showed that the effectiveness of solar energy depends on factors such as the productivity and efficiency of the photovoltaic system used, the climatic conditions and the density of the photovoltaic system employed based on the slope to horizontal conversion [48].

A minimum allocation of $70 \mathrm{~m}^{2}$ for each residential unit can generate about $12 \%$ of solar radiation into electricity. This depends on the local climatic conditions and daily availability of solar radiation. Generally, this natural and renewable resource must be taken into account within the designing stage to orient buildings to the sun. Car parks can be covered by a shading device to provide shade for visitors. The car parks are huge when compared with other open spaces within the university. Exploiting the car parking by applying a PV system within the shading device and generating energy in the form of electricity is an important retrofitting strategy within the current design of the university campus.

\section{Conclusion and Recommendations}

The paper investigated the urban sustainable design of the Albaha University campus in terms of its local site features and environmental condition. The study focused on how to develop open spaces and address the needs of students and staff members. A physical site visit survey was performed to identify the chances of developing the urban design of the university campus and exploit the huge open spaces within the university boundary. The analysis covered the current situation of the university design and the student capacity in different faculties. The impact of the university on local urban planning was analysed and the threats and weaknesses were identified using the SWOT methodology. The findings highlight that: (a) huge open spaces can be exploited and designed for social activities and facilities can be built that contribute to the local economy due to the influence of the university on the economic system of the region; (b) the university should be developed to employ natural resources to operate some of the facilities within the university; and (c) the university has many strengths that should be developed to counteract the many threats that the university can face. The study concludes by putting forward the following recommendations:

Environmentally:

1) To apply renewable energy technology such as (PV) panels to operate the accommodation zone of staff members.

2) To exploit the roofs of buildings for rainwater harvesting from open spaces and parks and reuse for irrigation and planting purposes.

3) To install shading device on the building to minimise energy consumption and reduce $\mathrm{CO}_{2}$ emissions.

4) To landscape the open spaces to provide green areas that play a significant role in a clean environment.

Economically:

1) To establish new faculties that can contribute to the development of local urban planning, such as agriculture and environment.

2) To develop the strong points of the Albaha University to avoid the threats and competition from surrounding universities.

3) To allocate new facilities in the university to serve students and staff members and allocate facilities that serve the local public and contribute to the local economy.

\section{Acknowledgements}

"This research is a part of a project and was funded by the Deanship of Scientific Research, Albaha University, KSA (Grant No. 1440 /25). This assistance of the deanship is gradually acknowledged."

\section{References}

[1] Al-Robai, S. A., et al., Vegetation structure and species diversity of Wadi Turbah Zahran, Albaha area, southwestern Saudi Arabia. Annals of Agricultural Sciences, 2017. 62 (1): p. 61-69.

[2] Alsumairi, M. and K. W. Hong Tsui, A case study: The impact of low-cost carriers on inbound tourism of Saudi Arabia. Journal of Air Transport Management, 2017. 62: p. 129-145.

[3] Bell, G. G. and L. Rochford, Rediscovering SWOT's integrative nature: A new understanding of an old framework. The International Journal of Management Education, 2016. 14 (3): p. 310-326.

[4] Fertel, C., et al., Canadian energy and climate policies: A SWOT analysis in search of federal/provincial coherence. Energy Policy, 2013. 63: p. 1139-1150.

[5] Kazemi, F., et al., Strategic planning for cultivation of fruit trees and shrubs in urban landscapes using the SWOT method: A case study for the city of Mashhad, Iran. Land Use Policy, 2018. 70: p. 1-9. 
[6] Sangkakool, T., et al., Prospects of green roofs in urban Thailand - A multi-criteria decision analysis. Journal of Cleaner Production, 2018. 196: p. 400-410.

[7] White, T. H., et al., Improving reintroduction planning and implementation through quantitative SWOT analysis. Journal for Nature Conservation, 2015. 28: p. 149-159.

[8] Halla, F., A SWOT analysis of strategic urban development planning: The case of Dar es Salaam city in Tanzania. Habitat International, 2007. 31 (1): p. 130-142.

[9] Şahin, N. İ. and G. Manioğlu, Water conservation through rainwater harvesting using different building forms in different climatic regions. Sustainable Cities and Society, 2019. 44: p. 367-377.

[10] Hu, W., et al., A Fast Prediction Model for Heat Transfer of Hot-Wall Heat Exchanger Based on Analytical Solution. Applied Sciences, 2019.9 (1): p. 72.

[11] Heim, D. and A. Wieprzkowicz, Attenuation of Temperature Fluctuations on an External Surface of the Wall by a Phase Change Material-Activated Layer. Applied Sciences, 2017. 8 (1): p. 11.

[12] Kheiri, F., A review on optimization methods applied in energy-efficient building geometry and envelope design. Renewable and Sustainable Energy Reviews, 2018. 92: p. 897-920.

[13] Shi, L., et al., Optimizing the thermal performance of building envelopes for energy saving in underground office buildings in various climates of China. Tunnelling and Underground Space Technology, 2018. 77: p. 26-35.

[14] Ghosh, A. and B. Norton, Advances in switchable and highly insulating autonomous (self-powered) glazing systems for adaptive low energy buildings. Renewable Energy, 2018. 126: p. 1003-1031.

[15] Liu, C., et al., Effect of PCM thickness and melting temperature on thermal performance of double glazing units. Journal of Building Engineering, 2017. 11: p. 87-95.

[16] Zhu, Y., et al., Analysis of heat transfer and thermal environment in a rural residential building for addressing energy poverty. Applied Sciences, 2018. 8 (11): p. 2077.

[17] Gassar, A. A. A. and G. Y. Yun, Energy Saving Potential of PCMs in Buildings under Future Climate Conditions. Applied Sciences, 2017.7 (12): p. 1219.

[18] Ziyaee, M., Assessment of urban identity through a matrix of cultural landscapes. Cities, 2018. 74: p. 21-31.

[19] McCormick, P. G. and H. Suehrcke, The effect of intermittent solar radiation on the performance of PV systems. Solar Energy, 2018. 171: p. 667-674.

[20] Rehman, S., M. A. Bader, and S. A. Al-Moallem, Cost of solar energy generated using PV panels. Renewable and Sustainable Energy Reviews, 2007. 11 (8): p. 1843-1857.

[21] Badescu, V., How much work can be extracted from diluted solar radiation? Solar Energy, 2018. 170: p. 1095-1100.

[22] Dong, K., et al., Energy intensity and energy conservation potential in China: A regional comparison perspective. Energy, 2018. 155: p. 782-795.

[23] Sun, W., et al., Environmental ideology and household energy conservation in Beijing. Journal of Cleaner Production, 2018. 195: p. 1600-1608.

[24] Lindelöf, D., et al., Bayesian verification of an energy conservation measure. Energy and Buildings, 2018. 171: p. $1-10$.

[25] Swann, W. L., et al., Community resistance and discretionary strategies in planning sustainable development: the case of Colorado cities. Urban Planning, 2019. 4 (4): p. 98-110.

[26] Washington-Ottombre, C., G. L. Washington, and J. Newman, Campus sustainability in the US: Environmental management and social change since 1970. Journal of Cleaner Production, 2018. 196: p. 564-575.

[27] dell'Olio, L., et al., A methodology based on parking policy to promote sustainable mobility in college campuses. Transport Policy, 2018.

[28] Jittrapirom, P., et al., Mobility as a service: A critical review of definitions, assessments of schemes, and key challenges. 2017.

[29] Nikolaidou, S., et al., Urban gardening and green space governance: Towards new collaborative planning practices. Urban Planning, 2016. 1 (1): p. 5-19.

[30] Teitelbaum, E. and F. Meggers, Expanded psychrometric landscapes for radiant cooling and natural ventilation system design and optimization. Energy Procedia, 2017. 122: p. 1129-1134.

[31] Laurini, E., et al., Analysis and exploitation of the stack ventilation in the historic context of high architectural, environmental and landscape value. Energy Procedia, 2017. 133: p. 268-280.

[32] Eizenberg, E., O. Sasson, and M. Shilon, Urban morphology and qualitative topology: Open green spaces in high-rise residential developments. Urban Planning, 2019. 4 (4): p. 73-85.

[33] Delwati, M., et al., Impact of demand controlled ventilation on system performance and energy use. Energy and Buildings, 2018. 174: p. 111-123.

[34] Zhang, T., et al., Ventilation, indoor particle filtration, and energy consumption of an apartment in northern China. Building and Environment, 2018. 143: p. 280-292.

[35] Zheng, S., et al., Influence of Trees on the Outdoor Thermal Environment in Subropical Areas: An Experimental Study in Guang Zhou, China. Sustainable Cities and Society, 2018.

[36] Tabb, A. and H. Medeiros, Automatic segmentation of trees in dynamic outdoor environments. Computers in Industry, 2018. 98: p. 90-99.

[37] Akbari, H., Shade trees reduce building energy use and $\mathrm{CO}_{2}$ emissions from power plants. Environmental Pollution, 2002. 116: p. S119-S126.

[38] Remøy, H., et al., Facilitating circular economy in urban planning. Urban Planning, 2019. 4 (3): p. 1-4.

[39] Bush, J., et al., Integrating green infrastructure into urban planning: Developing Melbourne's green factor tool. Urban Planning, 2021. 6 (1): p. 20-31.

[40] Shamseldin, A. K. M., Unifying some variables' effects among different environmental assessment methods of buildings. HBRC Journal, 2018. 14 (1): p. 93-103. 
[41] Saunders, T., A discussion document comparing international environmental assessment methods for buildings. BRE, March, 2008.

[42] Nesteby, A. I., et al., Integration of BREEAM-NOR in Construction Projects: Utilizing the Last Planner System. Energy Procedia, 2016. 96: p. 100-111.

[43] Liu, Y., et al., Occupant satisfaction in Three-Star-certified office buildings based on comparative study using LEED and BREEAM. Building and Environment, 2018. 132: p. 1-10.

[44] Seinre, E., J. Kurnitski, and H. Voll, Building sustainability objective assessment in Estonian context and a comparative evaluation with LEED and BREEAM. Building and Environment, 2014. 82: p. 110-120.
[45] Chen, Z., et al., Variable-Constrained Model Predictive Control of Coordinated Active Power Distribution for Wind-Turbine Cluster. Applied Sciences, 2018.9 (1): p. 112.

[46] Pillai, D. S. and N. Rajasekar, A comprehensive review on protection challenges and fault diagnosis in PV systems. Renewable and Sustainable Energy Reviews, 2018. 91: p. $18-40$.

[47] Killinger, S., et al., On the search for representative characteristics of PV systems: Data collection and analysis of PV system azimuth, tilt, capacity, yield and shading. Solar Energy, 2018. 173: p. 1087-1106.

[48] Bertrand, C., et al., Solar irradiation from the energy production of residential PV systems. Renewable Energy, 2018. 125: p. 306-318. 